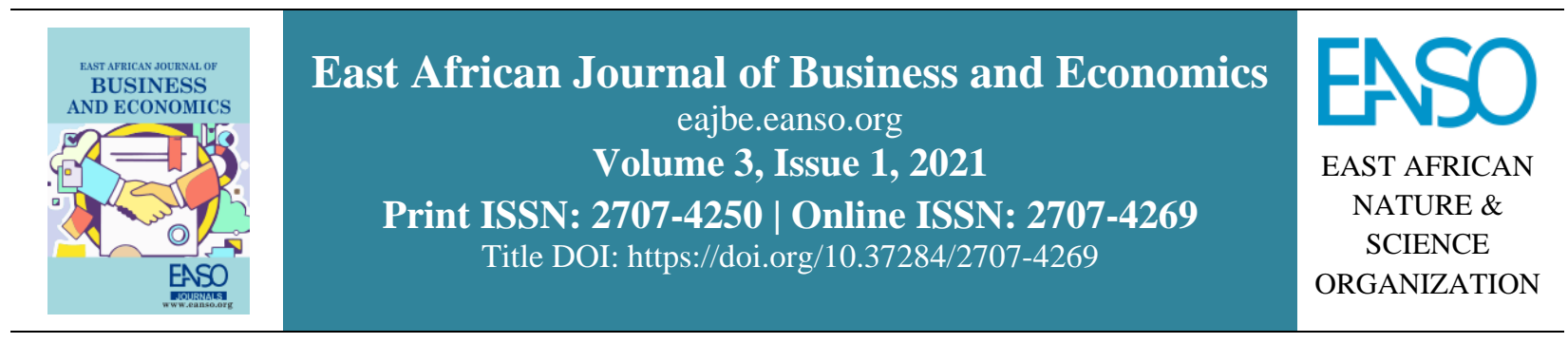

Original Article

\title{
Impact of Recruitment and Selection Process on the Performance of Public Enterprises. A Study of the Nigeria Railway Corporation.
}

\author{
Ayangeadoo Alphonsus Hur-Yagba $(P h D)^{1 *}$ \\ ${ }^{1}$ University of Abuja, PMB 117 Abuja, Nigeria. \\ *Correspondence email: alphonsus.hur-yagba@uniabuja.edu.ng.
}

Article DOI: https://doi.org/10.37284/eajbe.3.1.322

\section{Date Published: ABSTRACT}

24 April 2021 This study examined the impact of the recruitment and selection process on the performance of employees in the Nigerian Railway Corporation. The

Keywords: population of the study is six hundred and fifty-six (656) staff, and a sample

size of two hundred and forty-eight (248) was drawn using Taro Yamane's

Selection Process, Maintenance Culture,

Innovation,

Performance. sample size determination technique. Survey and interview methods were used for data collection. The Ordinary Least Squares method of regression was used to analysed the data. Findings revealed that the recruitment and selection process has a significant influence on the train movement schedule of the Corporation, and Hypothesis one was therefore rejected. It also discovered that the recruitment and selection process, on average, have significant effects on the train maintenance culture of the Corporation, and Hypothesis two was similarly rejected. Finally, it equally revealed that the recruitment and selection process greatly elicited employees' innovation, particularly in the recruitment source and recruitment selection policy, consequently rejecting Hypothesis three. The study concluded that the recruitment and selection process greatly influenced employees' performance in the Corporation regarding hiring appropriate skills that handled train movement schedules except for the train maintenance culture. The study recommended that the Corporation review recruitment hiring policy to focus on meritocracy and brace up to internal and external sources of hiring appropriate personnel for train maintenance in the Corporation. Also, there should be no government or political interference regarding recruitment source and recruitment policy as being done now to stimulate employee selection.

82 This work is licensed under a Creative Commons Attribution 4.0 International License. 


\section{APA CITATION}

Hur-Yagba, A. A. (2021). Impact of Recruitment and Selection Process on the Performance of Public Enterprises. A Study of the Nigeria Railway Corporation. East African Journal of Business and Economics, 3(1), 82-97. https://doi.org/10.37284/eajbe.3.1.322

\section{CHICAGO CITATION}

Hur-Yagba, Ayangeadoo Alphonsus. 2021. "Impact of Recruitment and Selection Process on the Performance of Public Enterprises. A Study of the Nigeria Railway Corporation:.". East African Journal of Business and Economics 3 (1), $82-97$. https://doi.org/10.37284/eajbe.3.1.322

\section{HARVARD CITATION}

Hur-Yagba, A. A. (2021) "Impact of Recruitment and Selection Process on the Performance of Public Enterprises. A Study of the Nigeria Railway Corporation.", East African Journal of Business and Economics, 3 (1), pp. 82-97. doi: 10.37284/eajbe.3.1.322.

\section{IEEE CITATION}

A. A. Hur-Yagba, "Impact of Recruitment and Selection Process on the Performance of Public Enterprises. A Study of the Nigeria Railway Corporation”, EAJBE, vol. 3, no. 1, pp. 82-97, Apr. 2021.

\section{MLA CITATION}

Hur-Yagba, Ayangeadoo Alphonsus. "Impact of Recruitment and Selection Process on the Performance of Public Enterprises. A Study of the Nigeria Railway Corporation”. East African Journal of Business and Economics, Vol. 3, no. 1, Apr. 2021, pp. 82-97, doi:10.37284/eajbe.3.1.322

\section{INTRODUCTION}

Nigerian Railway Corporation's performance has been on the decline for a very long time in Nigeria's history. Many reasons for such abysmal performance have been raised, ranging from employee-oriented factors to management inefficiencies and government support for the Corporation. Meanwhile, researches have shown that, for every organization, the human resource is usually the driving force behind its survival, growth and sustainability (Adeyemi, T.W, Dumade, \& Fadare, 2011; Djabatey, 2012). Obtaining relevant employee skills for effective and efficient operations usually begins from the process through which such employees are hired. That is the recruitment and selection process of these employees for the job they are hired to perform. And until this process is properly carried out, management efficiency normally remains elusive. Now going by the country's recruitment and selection process, which overtly embrace the quarter system, religious affiliation, Godfatherism and ethnicity as opposed to meritocracy, equality and transparency; our recruitment and selection exercise is usually bastardized and often marred with fraudulent activities such as recruitment based on ethnicity, 'Godfatherism', as well as corruption ingredients such as bribery, nepotism and many other forms of discrimination resulting to inappropriate recruitment and selection process of the Corporation's employees (Wanyama, 2009). However, available research has shown that an organization's recruitment and selection process's effectiveness can positively influence employees' performance (Petts, 2012; Cole, 2012; Bjorkman, 2009 \& Xiucheng, 2012).

Recruitment process entails a systematic procedure, from sourcing the candidates to arranging and conducting the interviews, which requires many resources and time. Recruitment process is also seen as a "positive procedure of generating a pool of candidates by reaching the appropriate audience, suitable to fill the vacancy" (Henry \& Temtime, 2009). According to him, after these candidates are identified, selecting appropriate employees for recruitment can begin. This means collecting, measuring, and evaluating information about candidates' qualifications for specified positions. Selection is choosing the most suitable applicant from the pool of applicants recruited to fill the relevant job vacancy. It can also be said to be the process by where specific instruments are employed to select from the pool of individuals most suitable for the available job. The selection process is the process of differentiating between applicants to identify (and hire) those with a greater likelihood of success in a job'. The processes involved in the selection process are: Inviting applications, 83 This work is licensed under a Creative Commons Attribution 4.0 International License. 
Receiving applications, Scrutiny of applications, Pencil and Paper tests, Psychological tests, Personal interview, Reference check, Medical examination, Final selection and Placement (Gamage, 2014; Henry \&Temtime, 2009).

On the other hand, performance is a continuous and flexible process that involves managers and those they manage acting as partners within a framework that sets out how they can best work together to achieve the required results. Performance is associated with quantity and quality of output, timeliness of production, presence on the job, the efficiency of the work completed, and work effectiveness (Mathis, 2009). Gibson (2009) went further to reiterate that employees' performance is measured in terms of productivity, job satisfaction, turnover and absenteeism." Employee performance is about the timely, effective and efficient completion of mutually agreed tasks by the employee, as set out by the employer.

Most of the Nigerian organizations and agencies have failed to function optimally because of these faulty standards set for recruitment and selection of employees into position vacancies. It is on record that the Nigerian Railway Corporation's operations have continually deteriorated or declined in the past four decades. The Nigerian Railway Corporation traced its history to 1898 , when the British colonial government constructed the first railroad in Nigeria. On October 3, 1912, the Lagos Government Railway and the Baro-Kano Railway were amalgamated, starting nationwide rail service under the name Government Department of Railways. With the passing of the Nigerian Railway Corporation Act of 1955, the company gained its current reputation and the exclusive legal right to construct and operate rail service in Nigeria (Ayoola, 2016).

The rail network services reached its peak in 1964 after Nigerian independence. Soon after that, the Nigerian Railway Corporation services entered a long period of decline, inept management, and a complete lack of maintenance of rail and locomotive assets. In 1988, the Nigerian Railway Corporation became bankrupt and its services were grounded. By 2002, passenger service again discontinued altogether.
In 2005 after several re-organizations of the system, passenger services were brought down to four departures weekly from Lagos, and two went to Kano. In 2006, plans to restore the rail lines were concluded and provisions to add new locomotives with foreign assistance were concretised. In December 2012, regular, scheduled passenger service restored on the Lagos to Kano line. In 2013, the Jonathan administration specifically promised to invest N1.6tn in the railway system in two years. About 15 different railway projects were pencilled down for completion by 2015 , and 13 of the projects were listed for attention in key federal ministries' capital projects for that year.

The Corporation's rejuvenation or resuscitation process only started genuinely in the last decade with President Goodluck Jonathan led Federal Government. Even then, the Corporation appeared to have been going through a restructuring of one form or the other. The Corporation is yet to fully take its proper place as a major transportation system in the country; whereas, its operations, if fully harnessed, will significantly reduce the pressure on passenger movement, cargo trailers, and oil tankers and increased revenue generation for the country.

In March 2017, the Vice President of Nigeria, Professor Yemi Osinbajo, who was acting president, commissioned the Lagos - Ibadan rail line project to run from Apapa Port in Lagos to Ibadan in Oyo state. This project was the second component of the Lagos-planned six components to Kano standard gauge rail track. The first was the Abuja - Kaduna $187 \mathrm{~km}$ rail line that was launched in July 2016. Others icluded Kaduna - Kano, Ibadan - Ilorin, Minna - Abuja and Ilorin - Minna.

Consequently, this study has examined the extent to which the independent variable (Recruitment and Selection Process) has influenced (positively or negatively) the dependent variable (Performance) and its subscales of train movement, train maintenance and employee innovation in Nigeria Railway Corporation.

\section{Research Questions}

- To what extent has Employee Recruitment and selection process significantly influenced the

84 | This work is licensed under a Creative Commons Attribution 4.0 International License. 
train movement schedule in Nigerian Railway Corporation?

- To what extent has Employee Recruitment and selection process greatly impacted Train Maintenance Culture in Nigerian Railway Corporation?

- To which degree has Employee Recruitment and selection process significantly elicited employees' innovation in Nigerian Railway Corporation?

\section{Statement of Hypotheses}

The above Research Questions have been translated into the following null hypotheses:

Ho1: Employee Recruitment and selection process did not significantly influence how train movement schedules in Nigerian Railway Corporation.

$\mathrm{H}_{0} 2$ : Employee Recruitment and selection process did not greatly impact Train Maintenance Culture in the Nigerian Railway Corporation.

$\mathrm{H}_{0} 3$ : Employee Recruitment and selection process did not significantly elicit employees' innovation in the Nigerian Railway Corporation.

\section{THEORETICAL FRAMEWORK}

This study is anchored on Barney's (1991) Resource-Based View theory which maintains that appropriate competitive advantage is possible when firms have a human resource pool that cannot be imitated or substituted by rivals. According to the Resource-Based view theory, firms should endeavour to regularly evaluate their workforce skills to ensure that the right people with relevant skills in the right places are provided for to guarantee enduring competitive advantage (Barney, 2001). Alternative, firms should make-up for the shortfall by employing appropriate recruitment and selection criteria. The theory insists that the major part of any firm's strength or weakness stem from the people's calibre and the quality of their working relationships. To this end, firms that recruit and retain exceptional individuals have the capability of generating human capital advantage. Invariably,
Technology and capital can be acquired by most firms at any time, for a price, but it is not easy to obtain a ready pool of highly qualified and motivated employees. Thus, to be differentiated, organizations need to be very careful with the recruitment and selection process.

\section{EMPIRICAL REVIEW}

Adeyemi, Dumade and Fadare (2011) assessed the impact of recruitment and selection on trains' time movement schedule in Japan. It was to assess the recruitment and selection policy or practice, the effect of the recruitment and selection process, as well as the challenges associated with the recruitment and selection practice, and ways to improve trains' time movement schedule. The study obtained data from Twenty (20) respondents from the Japan Railway Corporation staff through Questionnaire. Regression was used to analyse the data. The results showed that advertising of job vacancies to the general public, employment agent(s) and employee referrals are mostly the modes for recruiting potential employees. It also realized that the recruiting and selection process method was very effective and helped improve trains' timely movement. The study further revealed a significant positive relationship between recruitment and selection on train movement schedules.

Barney (2013) assessed the impact of recruitment and selection on trains' timely movement schedule in Newcastle, England. The study obtained information from one hundred and thirty (130) respondents from the Newcastle Railway Corporation staff through Questionnaire. ANOVA was used to analyze the data. The results displayed a significant positive relationship between recruitment and selection and the timely movement schedule of trains in Newcastle, England.

Biles and Holmberg (2017) evaluated the impact of recruitment and selection on trains timely movement schedule in Norway. Data was collected from the staff of Norway Railway Corporation through the use of the Questionnaire. Eighty-Four (84) respondents filled and returned their completed copies of the Questionnaire to analyze the data through the chi-square tool of analysis. The findings indicated a significant positive relationship between

85 This work is licensed under a Creative Commons Attribution 4.0 International License. 
recruitment and selection and timely movement schedule of trains in Norway Railway Corporation.

Cole (2012) evaluated the role of recruitment and selection on trains' timely movement schedule in Sheffield, England. The study obtained data from one thirty (30) respondents from the Sheffield Railway Corporation staff through the use of the Questionnaire. Chi-square was used to analyse the data. The results indicated no significant relationship between recruitment and selection and the timely movement schedule of trains in Sheffield Railway Corporation.

Mokaya, Mukhweso \& Njuguna (2014) examined the effect of recruitment practices on train maintenance in the Kenya Railway Corporation, using Kenya Railway Corporation (KERC) Limited as a case study. The study addressed three research objectives: determining the extent to which recruitment sources, recruitment policies, and recruitment messages affect train maintenance in Kenya Railway Corporation. The study developed a case study research design. The study population was 177 employees of KERC. A sample size of 89 respondents was drawn for the study. The sample was selected through a stratified sampling technique. Primary data was collected through a Questionnaire, whereas secondary data was obtained through existing literature related to the current research topic under consideration. Data was analyzed using descriptive statistical tools. Inferential statistical tools were used to determine and explain the variable relationship. The study establishes that all three independent variables (recruitment sources, recruitment policies, recruitment message) had a positive relationship with the dependent variable (train maintenance) though weaker relationship.

Obikeze and Obi (2014) investigated the effect of recruitment and selection on trains' maintenance in the Railway Company of Istanbul, Turkey. Spraying ballast with herbicide to prevent weeds from growing through and redistributing the ballast is typically done with a special weed killing train. Over time, the ballast is crushed or moved by the weight of trains passing over it, periodically requiring revelling ("tamping") and eventually to be cleaned or replaced. Four hundred employees were sampled, and a regression method of data analysis used to analyze data. It revealed that rails must be replaced before the railhead profile wears to the degree that may trigger a derailment. Worn mainline rails usually have sufficient life remaining to be used on a branch line, siding or stub afterwards and are "cascaded" to those applications. The study further revealed no significant positive relationship between recruitment and selection on the maintenance of trains in the Railway Company of Istanbul, Turkey.

Djabatey (2012) examined the effects of recruitment and selection on a train maintenance schedule in New Delhi, India. The study collected information from Ninety-Three (93) respondents of Newcastle Railway Corporation through the Questionnaire. Chi-square was used to analyse the data, and the results indicated a significant positive relationship between recruitment and selection and train maintenance in New Delhi, India.

Ehlers \& Lazenby (2014), assessed the impact of recruitment and selection on train maintenance in Minnesota, United States of America. Data was collected from Thirty-One (31) respondents of Minnesota Railway Corporation through the use of the Questionnaire. Regression analysis was carried out. The results indicated no significant relationship between recruitment and selection and train maintenance in Minnesota, United States of America.

Ezeali, \& Esiagu (2010), evaluated the effects of recruitment and selection on train maintenance in Nigeria Railway Corporation, Headquarters in Lagos. The study collected data from Forty-One (41) respondents of Nigeria Railway Corporation, Headquarters in Lagos through the Questionnaire. Chi-square was used to analyse the data. This results indicated a significant positive relationship between recruitment and selection and train maintenance in Nigeria Railway Corporation, Headquarters in Lagos.

Kaplan and Norton (2015) assessed the impact of recruitment and selection on train maintenance in Chicago, United States of America. The study obtained information from one hundred and eleven (111) respondents of Chicago Railway Corporation through the Questionnaire. T-test was used to analyse the data, and the results indicated a

86 This work is licensed under a Creative Commons Attribution 4.0 International License. 
significant positive relationship with recruitment and selection and train maintenance in Chicago Railway Corporation.

Omisore and Okofu (2014) attempted to examine staff recruitment and selection process in the Nigeria Railway Corporation and its impact on the employees' innovation. Five (5) relevant research questions were raised and addressed. Descriptive statistics aws used to analyse the data collected from the respondents. The results obtained showed that merit was often jettisoned on the altar of ethnicity and religion in recruitment into the Nigerian Railway Corporation. Since the public service is directly controlled and regulated by the government, the Nigerian Federal Character Principle largely complies. The study also reveals that although there are stipulated periods for recruitment and selection into the public service, these are often sidelined. The study showed that the recruitment and selection process does not significantly influence employees' innovation in the Nigerian Railway Corporation.

Sinha \& Thaly (2013) investigated the effect of recruitment and selection on employees' innovation in Ireland's Railway Corporation. Employee innovation in the workplace includes among others introducing new technologies and techniques, suggesting new ways to achieve objectives, trying new ways of performing work tasks, and facilitating new ideas. The correlation was the tool of analysis used. The findings revealed that employee innovation includes both the introduction and the application or implementation of new ideas, products, processes, and procedures. This definition thus consists of a variety of behaviours on the innovation processes in an organization.

Mullins (2017) examined the effects of recruitment and selection on Dublin, Ireland's employees' innovation. Data was obtained from Sixty-Two (62) respondents of Ireland Railway Corporation through the Questionnaire. Chi-square was used to analyse the data, and the results indicated a significant positive relationship between recruitment and selection and employees' innovation in Ireland Railway Corporation.

Niven (2016) assessed the role of recruitment and selection of employees' innovation in Pakistan.
Data was collected from Ninety-Nine (99) respondents of Pakistan Railway Corporation with the aid of Questionnaire. ANOVA was used to analyse the data, and the results indicated no significant relationship between recruitment and selection and employees' innovation in Pakistan Railway Corporation.

\section{DESIGN AND METHODOLOGY}

This study covers five variables: the recruitment and selection (Independent) Variable, the performance (dependent) variable, its subscales of train movement schedules, train maintenance and employee innovation. The study also covers ten years (2007 -2017) of the Corporation's recruitment and selection exercise. This reason for this period is because it coincide with when politicians started having a stronghold on the recruitment and selection exercise into government offices/Agencies and most organizations; and meritocracy started giving way for ethnicity and religious considerations, among others. The materials covered include the recruitment records at different stages, adverts, and performance outcomes based on the above variables.

\section{The population of the Study and Sample Size}

The population of this study as shown in Appendix II attached, is 656 across 9 Departments of the Corporation and a sample size of 248 was randomly selected across these departments using Taro Yamane (1967)'s sample size determination technique.

$$
\frac{\mathrm{n}=\mathrm{N}}{1+\mathrm{N}(\mathrm{e})^{2}}
$$

Where; $\mathrm{N}=$ Population size $\mathrm{n}=$ Sample size and $\mathrm{e}=$ Error of Margin (0.05)

\section{Research Instrument and Data collection}

The basic instrument used for data collection was a well-structured questionnaire. The Questionnaire was administered to the staff of Nigerian Railway Corporation Headquarters, Lagos. Data were collected through Questionnaire and personal interviews. Three hundred copies of Questionnaire were distributed to workers of the Nigerian Railway Corporation across Department (Civil Engineering

87 This work is licensed under a Creative Commons Attribution 4.0 International License. 
Department, mechanical/ Electrical \& signal and Telecommunication Department, Operation and Commercial Department, Finance and Account Department, Administration/Human Resource Department, New Line Department, Corporate Planning Department, Audit Department and Medical Department). 252 copies were retrieved, 250 were properly completed and returned, and on the strength of Taro Yamane formula of sample determination, 248 copies were used (see Appendix II attached),

Furthermore, some personal interviews were also conducted to complement the responses of the Questionnaire. Eighteen senior executive officers were interviewed on some of the performance variables studied. Their responses contributed significantly to shaping the outcomes of our results.

\section{Analysis and Model Specification}

The relationship between recruitment and selection process and performance of Nigerian Railway Corporation was tested using the Ordinary Least Squares method of regression. It is one of the most widely accepted used methods for regression analysis. However, this is usually used to establish whether one variable is dependent on another or a combination of other variables.

Furthermore, multiple models were also used to estimate the impact of the recruitment and selection process on the Nigerian Railway Corporation's employee performance. Proxies of performance used are timely train movement schedule, train maintenance, and employee innovation and is expressed as thus:

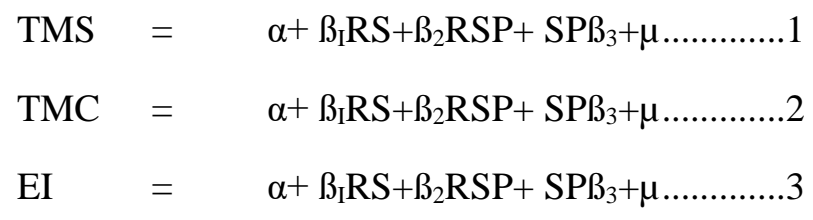

Where:

$\begin{array}{lll}\text { TMS } & = & \text { Train Movement Schedule } \\ \text { TMC } & = & \text { Train Maintenance Culture } \\ \text { EI } & = & \text { Employee Innovation } \\ \alpha & = & \text { Intercept } \\ \beta_{\mathrm{I}} & = & \text { Independent variable } \\ \mu & = & \text { Error term }\end{array}$

Also, where (RS= Recruitment Source, RSP= Recruitment and Selection Policy, SP= Selection Process) are Recruitment and Selection Process measures. Statistical Package for Social Sciences (SPSS) 23.0 Software employed to aid in our hypotheses' test.

\section{Correlation}

All the independent variables subscales of the Recruitment and Selection Process positively correlated with the dependent variables subscales. Recruitment Source positively correlated with Train Movement Schedule (TMS), Train Maintenance Culture (TMC) and Employee Innovation (EI) [0.448, 0.995 and 0.026], respectively. The correlation for Train Maintenance is highest, followed by Train Movement Schedule and then Employee Innovation.

Recruitment Source (RS) correlated positively with Train Movement (0.448), Train Maintenance (0.995) and Employee Innovation (0.026). Recruitment Selection Policy (RSP) had the highest positive correlation with Train Maintenance (0.811) followed by Employee Innovation (0.509) and Train Movement Schedule (0.027). Selection Process (SP) also positively correlated better with Employee Innovation (0.381) followed by Train Maintenance (0.122) and Train Movement Schedule (0.027).

On the whole, Train Maintenance Culture had the highest correlation with Recruitment Source (0.995), Train Movement Schedule also had the highest correlation with Recruitment Source (0.448) and Employee Innovation correlated best with Recruitment Selection Process (0.500). See Table 1 below:

88 This work is licensed under a Creative Commons Attribution 4.0 International License. 
East African Journal of Business and Economics, Volume 3, Issue 1, 2021

Article DOI: https://doi.org/10.37284/eajbe.3.1.322

Table 1: Correlations Coefficients for Employee Recruitment and Selection Process relationship with Train Movement Schedule (TMS), Train Maintenance Culture (TMC) and Employee Innovation (EI).

\begin{tabular}{lllllll}
\hline & TMS & TM & EI & RS & RSP & SP \\
TMS & 1 & & & & & \\
TMC & .503 & 1 & & & & \\
EI & .024 & .576 & 1 & & & \\
RS & .448 & .995 & .026 & 1 & & \\
RSP & .027 & .811 & .500 & .766 & 1 & \\
SP & .027 & .122 & .381 & .972 & .237 & 1 \\
\hline
\end{tabular}

Source:SPSSoutput,

Key:

TMS

TM

EI

\section{Testing Hypotheses:}

\section{Hypothesis One}

$\mathrm{Ho}_{1:}$ Employee Recruitment and selection process did not significantly influence the way train movement schedules in Nigerian Railway Corporation.

The regression analysis results in Table 1a below indicated that the Recruitment Selection Policy (RSP) and Selection Process (SP) significantly predicted Nigerian Railway Corporation's timely Train Movement Schedule. In contrast, Recruitment Source (RS) did not. The result shows that "Recruitment Source", which yielded a Beta $(\beta)$ value of $0.571, \mathrm{t}$-value of 0.806 , and a $\mathrm{p}$-value of 0.421 , was not significant since the p-value is greater than 0.05 level of significance. This means that the problem of train movement schedule is not traceable to the source of recruitment but purely from the recruitment policy, particularly the selection process. This implies that a unit change in the level of Recruitment Source (a unit increase or decrease) will not significantly have a corresponding effect on the Train Movement

\section{RS Recruitment Source \\ RSP Recruitment Selection Policy \\ SP Selection Process}

Schedule. The variable "Recruitment Selection policy" that yield a Beta $(\beta)$ value of 0.305 , t-value of 2.090, and a p-value of 0.038 , was significant since the $p$-value was less than 0.05 level of significance. This implies that a unit change in the recruitment selection policy (a unit increase or decrease) will significantly affect the train Movement Schedule.

However, the variable "Selection Process", which yielded a Beta $(\beta)$ value of 0.254 , t-value of 2.066 , and a p-value of 0.040 , was significant since the pvalue is less than 0.05 level of significance. This implies that a unit change in the Selection process level (a unit increase or decrease) will significantly predict the Train Movement Schedule. On average, Hypothesis One $\left(\mathrm{Ho}_{1}\right)$, which states that "Recruitment and Selection Process do not positively influence train movement schedule in Nigerian Railway Corporation", is rejected.

The regression model is stated as follows:

$$
\begin{gathered}
T M S=0.571 R S+0.305 R S P+0.254 S P+3.518 \\
\text { Equation } 1
\end{gathered}
$$


Table 1a: Regression Output for the Relationship among Recruitment and Selection Variables (RS, RSP, SP), and the Train Movement Schedule (TMS).

\begin{tabular}{|c|c|c|c|c|c|}
\hline \multicolumn{6}{|l|}{ Coefficients $^{\mathrm{a}}$} \\
\hline \multirow[t]{2}{*}{ Model } & \multicolumn{2}{|c|}{$\begin{array}{l}\text { Unstandardized } \\
\text { Coefficients }\end{array}$} & \multirow{2}{*}{$\begin{array}{l}\text { Standardized } \\
\text { Coefficients } \\
\text { Beta }\end{array}$} & \multirow[t]{2}{*}{$\mathrm{T}$} & \multirow[t]{2}{*}{ Sig. } \\
\hline & $\mathrm{B}$ & Std. Error & & & \\
\hline (Constant) & 3.518 & .428 & & 8.213 & .000 \\
\hline Recruitment Source & .571 & .071 & .506 & .806 & .421 \\
\hline $\begin{array}{l}\text { Recruitment Selection } \\
\text { Policy }\end{array}$ & .305 & .062 & .316 & 2.090 & $.038 *$ \\
\hline Selection Process & .254 & .061 & .300 & 2.066 & $.040 *$ \\
\hline
\end{tabular}

* Significant, $\mathrm{p}<0.05 \mathrm{a}$. Dependent Variable: Train Movement Schedule

Source: SPSS output

This implies that the regression model, as shown in Equation 1, significantly explained the predictability of Recruitment Source (RS), Recruitment Selection Policy (RSP) and Selection Process (SP) on the Nigerian Railway Corporation's performance variable 'Train Movement Schedule.' Also, an $\mathrm{R}^{2}$ of 0.439 indicates that only $43.9 \%$ of the variability in the Nigerian Railway Corporation's employees' performance is accounted for by the independent variables; it follows then that other extraneous variables could be responsible for the remaining $56.1 \%$ variability not explained as can be observed in the table $1 \mathrm{~b}$ below.

Table 1b: Model Summary

\begin{tabular}{lllll}
\hline Model & $\mathrm{R}$ & R Square & Adjusted R Square & $\begin{array}{l}\text { Std. Error of the } \\
\text { Estimate } \\
1\end{array}$ \\
\hline
\end{tabular}

a. Predictors: (Constant), Recruitment and Selection, Recruitment Source, Recruitment and Selection

Policy and Train Timely Movement schedule

Source: SPSS output

\section{Hypothesis Two}

$\mathrm{H}_{02}$ : Employee Recruitment and selection process did not greatly impact the state of Train Maintenance Culture in Nigerian Railway Corporation.

The regression analysis results in Table 2a below showed that Recruitment Selection Policy (RSP), Selection Process (SP), and Train Maintenance Culture (TMC) did not significantly predict Nigerian Railway Corporation's train Maintenance state. In contrast, Recruitment Source (RS) did significantly predict the Train Maintenance Culture.

The result shows that 'Recruitment Source', which yielded a Beta ( $\boldsymbol{\beta})$ value of 0.380 , $t$-value of 4.015 , and a p-value of 0.036 , was significant since the $p$ value is less than 0.05 level of significance. This implies that a unit change in the level of Recruitment Source (a unit increase or decrease) will significantly have a corresponding effect on the Train Maintenance Culture (0.380). Also, the variable 'Recruitment Selection Policy', which yielded a Beta ( $\boldsymbol{\beta})$ value of 0.820 , $t$-value of 0.124 , and a p-value of 0.902, was not significant; the pvalue is greater than 0.05 level of significance. Here, only the recruitment source is significant. The Recruitment Selection Policy and Selection Process are not significant, meaning Recruitment Selection Policy and the Selection Process greatly accounted for the sustenance of the maintenance culture of trains in the Nigerian Railway Corporation. This implies that a unit change in the recruitment and selection policy level (a unit increase or decrease) will not significantly affect the train Maintenance.

90 This work is licensed under a Creative Commons Attribution 4.0 International License. 
Also, the variable 'Selection Process', which yielded a Beta ( $\boldsymbol{\beta})$ value of 0.987 , t-value of 1.533, and a p-value of 0.627 , was not significant since the p-value is not less than 0.05 level of significance. This implies that a unit change in the Selection Process level (a unit increase or decrease) will not significantly predict Train Maintenance Culture in Nigeria. Hypothesis Two $\left(\mathrm{Ho}_{2}\right)$, which states that 'Employee Recruitment and selection process do not significantly affect the state of Train Maintenance Culture in Nigerian Railway Corporation" was, therefore, rejected. (see Table 2a below)

The regression model is stated as follows:

$T M=0.380 R S+0.820 R S P+0.987 S P+$ 3.400 Equation 2

Table 2a: Regression Output for the Relationship among Recruitment and Selection Variables (RS, RSP, SP), and the Train Maintenance Culture (TMC)

\begin{tabular}{|c|c|c|c|c|c|}
\hline \multicolumn{6}{|l|}{ Coefficients $^{\mathrm{a}}$} \\
\hline \multirow{2}{*}{ Model } & \multicolumn{2}{|c|}{$\begin{array}{l}\text { Unstandardized } \\
\text { Coefficients }\end{array}$} & \multirow{2}{*}{$\begin{array}{l}\text { Standardized } \\
\text { Coefficients } \\
\text { Beta }\end{array}$} & \multirow[t]{2}{*}{$\mathrm{T}$} & \multirow{2}{*}{ Sig. } \\
\hline & B & Std. Error & & & \\
\hline (Constant) & 3.400 & .455 & & 7.481 & .000 \\
\hline Recruitment Source & .380 & .075 & .322 & 4.015 & $.036^{*}$ \\
\hline $\begin{array}{l}\text { Recruitment Selection } \\
\text { Policy }\end{array}$ & .820 & .066 & .790 & .124 & .902 \\
\hline Selection Process & .987 & .064 & .979 & 1.533 & .627 \\
\hline
\end{tabular}

* Significant, $\mathrm{p}<0.05 \mathrm{a}$. Dependent Variable: Train Maintenance

Source: SPSS output

Also, an $\mathrm{R}^{2}$ of 0.410 indicates that only $41.0 \%$ of the variability in the Nigerian Railway Corporation employees' performance can be accounted for by the independent variables, it follows that other extraneous variables could be responsible for the remaining $59.0 \%$ variability observed as presented in the table $2 \mathrm{~b}$ below.

Table 2b: Model Summary

\begin{tabular}{lllll}
\hline Model & $\mathrm{R}$ & R Square & Adjusted R Square & $\begin{array}{l}\text { Std. Error of the } \\
\text { Estimate }\end{array}$ \\
1 & $.599^{\mathrm{a}}$ & .410 & .302 & 1.09111 \\
\hline
\end{tabular}

a. Predictors: (Constant), Selection Process, Recruitment Source, Recruitment and Selection Policy and Train Maintenance.

Source: SPSS output

\section{Hypothesis Three}

$\mathrm{H}_{03} \quad$ Employee Recruitment and selection process did not significantly elicit employees' innovation in the Nigerian Railway Corporation.

The regression analysis results in Table 3 a revealed that Recruitment Source (RS) and Recruitment Selection Policy (RSP) significantly predicted Nigerian Railway Corporation's Employee Innovative ability. In contrast, the Selection Process did not significantly predict the Employees'
Innovation ability. The result indicates that 'Recruitment Source', which yielded a Beta $(\boldsymbol{\beta})$ value of 0.619 , t-value of 2.228 , and a p-value of 0.027 , was significant since the p-value is less than 0.05 level of significance. This implies that a unit change in the level of Recruitment Source (a unit increase or decrease) will significantly affect Employee Innovation. Also, the variable 'Recruitment Selection policy', which yielded a Beta ( $\boldsymbol{\beta})$ value of 0.425 , t-value of 0.706 , and a $p$ value of 0.041 , is also significant $p$-value is less than 0.05 level of significance. This equally implies that

91 This work is licensed under a Creative Commons Attribution 4.0 International License. 
a unit change in the recruitment selection policy (a unit increase or decrease) will significantly affect Employee Innovation. The variable 'Selection Process' and innovation yielded a Beta $(\boldsymbol{\beta})$ value of $0.578, \mathrm{t}$ - a value of 0.930 , and a $\mathrm{p}$-value of 0.353 were not significant since the $\mathrm{p}$-value is greater than the 0.05 level of significance. This implies that a unit change in recruitment and Selection and Innovation (a unit increase or decrease) will not significantly predict Employee innovation.
Hypothesis Three $\left(\mathrm{H}_{03}\right)$, which states that "Employee Recruitment and selection process do not significantly elicit employees' innovation in Nigerian Railway Corporation." was rejected.

The regression model is stated as follows:

$$
\begin{gathered}
E I=0.619 R S+0.452 R S P+0.578 S P+3.970 \\
\text { Equation } 3
\end{gathered}
$$

Table 3a: Regression Output for the relationship between Recruitment and Selection Variables (RS, RSP, SP), and Employees' Innovation (EI)

\begin{tabular}{llllll} 
Coefficients & \multicolumn{2}{l}{$\begin{array}{l}\text { Unstandardized } \\
\text { Coefficients }\end{array}$} & $\begin{array}{l}\text { Standardized } \\
\text { Coefficients }\end{array}$ & \multirow{2}{*}{ T } & \multirow{2}{*}{ Sig. } \\
\cline { 2 - 4 } & $\mathrm{B}$ & Std. Error & Beta & & \\
\hline (Constant) & 3.970 & .439 & & 9.044 & .000 \\
Recruitment Source & .619 & .073 & .408 & 2.228 & $.027^{*}$ \\
Recruitment and Selection & .452 & .064 & .448 & .706 & $.041^{*}$ \\
Policy & .578 & .062 & .590 & .930 & .353 \\
Selection Process & .578 & & \\
\hline
\end{tabular}

* Significant, $\mathrm{p}<0.05 \mathrm{a}$. Dependent Variable: Employee Innovation

Source: SPSS output

Also, an $\mathrm{R}^{2}$ of 0.425 indicates that only $42.5 \%$ of the variability in the Nigerian Railway Corporation's performance can be accounted for by the independent variables; other extraneous variables could be responsible for the remaining $57.5 \%$ variability observed, as shown in table $3 \mathrm{~b}$ below.

Table 3b: Model Summary

Model Summary

\begin{tabular}{lllll}
\hline Model & $\mathrm{R}$ & R Square & Adjusted R Square & $\begin{array}{l}\text { Std. Error of the } \\
\text { Estimate }\end{array}$ \\
1 & $.559^{\mathrm{a}}$ & .425 & .413 & 1.05380 \\
\hline
\end{tabular}

a. Predictors: (Constant), Recruitment Source, Recruitment and Selection Policy, Selection Process and Employees Innovation.

Source: SPSS output

\section{DISCUSSION OF FINDINGS}

All the independent variables subscales correlated positively with the dependent variable subscales; however, the strength of the relationship or association varied with each subscale variable.

For Hypothesis One $\left(\mathrm{Ho}_{1}\right)$, the regression analysis results showed that the Recruitment Selection policy (0.038), as well as Selection Process (0.040), significantly predicted train movement schedule in the Nigerian Railway Corporation. At the same time, Recruitment Source (0.421) did not (see Table 1 above). While Recruitment Selection Policy yielded a Beta $(\beta)$ value of 0.308 , at - Value of 2.090 and a significance value of $0.038, \mathrm{P}=0.05$; the Selection Process yielded a Beta $(\beta)$ value of 0.254 , at - value of 0.066 and a significance value of 0.040 , and $P=0.05$. Recruitment Source yielded a Beta $(\beta)$ value of 0.571 , at - value of 0.806 and a

92 This work is licensed under a Creative Commons Attribution 4.0 International License. 
significance value of $0.421, \mathrm{P}-0.05$ (i.e. $\mathrm{P}$-value is greater than 0.05 ).

Also, the $\mathrm{R}^{2}$ value (see Table $1 \mathrm{~b}$ above) of 0.439 shows that only $43.9 \%$ of the variability in the Nigerian Railway Corporation's employee performance was accounted for by the independent variables. Therefore, it follows that other extraneous variables such as Government interference in the Recruitment and selection process through Godfatherism or religious influence and other fraudulent vices deployed for recruitment and selection process in the Corporation would have accounted for the remaining $56.1 \%$ of the variability. Consequently, the Null Hypothesis $\left(\mathrm{Ho}^{1}\right)$ was rejected, meaning Employee Recruitment and Selection Process has significantly influenced the performance (the relevant skills that would have optimally managed train movement schedule) of Nigerian Railway Corporation's employees, especially in both the Recruitment Policy and Selection Process.

The implication is that there is no problem with the Recruitment Source, from where the Potential employees are hired into the Nigerian Railway Corporation. The problem is actually with the Recruitment Policy and the Selection Process. This finding is consistent with the previous studies (Adeyemi, Dumade and Fadare, 2011; Cole, 2012; and Biles, \& Holmberg, 2017).

For Hypothesis Two, all the independent variables subscales correlated positively with the dependent variable subscales. The Regression analysis results in Table 2a above shows that the Recruitment and Selection Policy (0.902) and Recruitment and Selection Process (0.627) did not predict significantly train maintenance in Nigerian Railway Corporation, except for Recruitment Source, which significantly predicted train maintenance (0.036). The results showed that Recruitment Selection Policy yielded a Beta $(\beta)$ value of 0.820 , at-value 0.124 and a significance value $0.902, \mathrm{P}=0.05$; while Recruitment Selection Process yielded a Beta $(\beta)$ value of $0 . p 87$, at-value 1.533 and a significance value of $0.627, P=0.05$. Recruitment Source yielded a Beta $(\beta)$ value of 0.380 , at-value 4.015 and a significance value of $0.036, \mathrm{P}=0.05$.
The implication is that both the Recruitment Selection Policy and the Recruitment Selection Process did not significantly predict the train maintenance culture of employees in the Corporation. In contrast, Recruitment Source significantly predicted the train maintenance culture of the Corporation's employees. This suggests that, while the Recruitment Source is a major factor inhibiting the employment of the needed qualified engineers from maintaining the Corporation's trains; on the average, Recruitment Selection Policy and Recruitment Selection Process has not so far, shown to be responsible for poor train maintenance culture in the Nigerian Railway Corporation.

The $\mathrm{R}^{2}$ of 0.410 shows that only $41.0 \%$ of the variability in the Nigerian Railway Corporation's employees' performance can be accounted for by the independent variables. It thus, follows that other extraneous variables could be responsible for the remaining 59\% variability, as observed in Table $2 \mathrm{~b}$ above. Therefore, hypothesis Two $\left(\mathrm{Ho}_{2}\right)$ was rejected, meaning the Recruitment Selection Process has a significant effect on the train maintenance process in the Nigerian Railway Corporation. This finding supports previous literature (Mokaya, J.R. Mukhweso \& Njuguna, 2014; Ezeali, \& Esiagu, 2010 and Kaplan \& Norton, 2015 )

In line with Hypothesis Three, all the independent variables subscales correlated positively with the dependent variable subscales. The Regression results in Table 3a above indicate that Recruitment Source (0.027) and Recruitment Selection Policy (0.041) significantly predicted employee innovation in the Corporation, while the Recruitment Selection Process (0.353) did not. Meanwhile, Recruitment Source yielded a Beta $(\beta)$ value of 0.619 , at-value of 2.228 and a significance value of 0.027 , at $P=0.05$; Recruitment Selection Policy yielded a Beta $(\beta)$ value of 0.452 , at-value of 0.706 and a significance value of 0.041 at $P=0.05$. Recruitment Selection Process yielded a Beta $(\beta)$ value of 0.578 , at-value of 0.930 and a significance value of $0.353, P=0.05$.

The $\mathrm{R}^{2}$ value (see Table $3 \mathrm{~b}$ above) of 0.425 allude that only $42.5 \%$ of the variability in the Nigerian Railway Corporation's employee performance can be accounted for by the independent variables. This follows that other extraneous variables accounted

93 This work is licensed under a Creative Commons Attribution 4.0 International License. 
for the remaining $57.5 \%$ of the variability. The Null Hypothesis $\left(\mathrm{Ho}_{3}\right)$ was, in this way, rejected, meaning Recruitment Source and Selection Process has significantly influenced the performance of Nigerian Railway Corporation's employees.

The implication is that there is no problem with the Recruitment Source by which potential employees are brought into the Nigerian Railway Corporation's services regarding employees' level of innovation. The problem is actually with the Recruitment Selection Policy and the Selection Process. These findings correlate with previous literature studies (Mullins, 2017; \& Niven, 2016).

\section{Findings:}

From the preceding, the results of the hypotheses tested revealed the following:

- Findings based on Hypothesis One $\left(\mathrm{Ho}_{1}\right)$ revealed that the recruitment and Selection Process (Recruitment Source, Recruitment Selection Policy, Selection Process) significantly influences the Train Movement Schedule of the Corporation. The detailed analysis showed that, except for Recruitment Source, which had no significant effect $(0.421)$ on Train Movement Schedule, Recruitment Selection Policy $\left(0.038^{*}\right)$ as well as Selection Process $\left(0.040^{*}\right)$ greatly influenced Train Movement Schedule. This finding agrees with previous studies (Adeyemi, Dumade \& Fadare 2011; Richard (2009); Ekwoaba, Ikeiji, \& Ufoma, 2015; Subbarao, 2015; Richard 2009). This has resulted in the rejection of Hypothesis One $\left(\mathrm{Ho}_{1}\right)$, which states that "Recruitment and Selection Process does not positively influence Train Movement Schedule in Nigerian Railway Corporation."

- Findings based on Hypothesis Two $\left(\mathrm{Ho}_{2}\right)$ revealed that the Recruitment and Selection Process also, on average, have significant effects on train maintenance Culture in Nigerian Railway Corporation as affirmed by the majority of the respondents, especially with regards to Recruitment Selection Policy (0.902) and Selection process (0.627). However, Recruitment Source (.036) remains an exception. This agrees with previous studies (Mokaya,
Mukhweso \& Njuguna, 2014; Djabatey, 2012; Ehlers \& Lazenby, 2014; Ezeali, B. O \& Esiagu, 2010; and Kaplan \& Norton 2015). Therefore, we reject Hypothesis Two, which states that: "Employee Recruitment and selection process do not significantly affect the state of train maintenance in Nigerian Railway Corporation" was, therefore, accepted.

- Findings on Hypothesis Three revealed that Recruitment and Selection Process on average does not significantly elicit employees' innovation in the Nigerian Railway Corporation, particularly in terms of Recruitment Source $\left(0.027^{*}\right)$ and Recruitment Selection Policy $\left(0.041^{*}\right)$, only Selection Process (0.353) had sparingly elicited employees' innovation in the Corporation. This result correlates with previous studies (Sinha \& Thaly 2013; Omisore \& Okofu 2014; Mullins, 2017 \& Niven, 2016). Hypothesis Three $\left(\mathrm{Ho}_{3}\right)$, which states that "Employee Recruitment and selection process did not significantly elicit employees' innovation in Nigerian Railway Corporation. was Rejected.

\section{CONCLUSIONS}

The study concludes that the Recruitment and Selection Process greatly influenced employees' performance in the Nigerian Railway Corporation concerning Recruitment Selection Policy and Selection Process in terms of hiring appropriate skills that have been handling the schedules of Train Movement and innovation, as can be seen in the results of Hypotheses One and Three; except for the Train Maintenance Culture of these employees ability in the Corporation as evidenced in Hypothesis Two which did not significantly affect the corporations' employees train maintenance's culture.

\section{RECOMMENDATIONS}

The study recommended the following based on the findings and in line with the objectives of the study:

- The Management of the Nigerian Railway Corporation should review her recruitment hiring policy and the Selection Process to focus on meritocracy as opposed to hiring based on ethnic considerations, religious affiliation as

94 This work is licensed under a Creative Commons Attribution 4.0 International License. 
well as Godfatherism, among others, while consolidating on Recruitment Source; to be able to get the right skills that will handle efficiently, the scheduling of Train Movement in the Corporation.

- Attention should be paid to the recruitment source (employment pool), which should widely include internal and external sources to get the right skills that will provide the needed technical skills that will manage effectively, train maintenance culture in Nigerian Railway Corporation. Recruitment Selection Policy and Selection Process currently in use should be maintained to enhance train maintenance services further.

- Recruitment source as well as Recruitment selection policy are not significant and should be encouraged. These two activities should be free from every form of interferences to stimulate employees' innovation among workers in the Corporation. The Selection Process is not significant concerning the innovative ability of workers.

\section{REFERENCES}

Adeyemi, T.W, Dumade, H.K and Fadare, G.A (2011). Impact of Recruitment and Selection on

Organizational Performance. Journal of Abnormal and Social Psychology, 67, 422-434.

Ayoola, T. A. (2016). "Establishment of the Nigerian Railway Corporation." Journal of Retracing Africa: Vol. 3, Issue 1: 21-42. from https://encompass.eku.edu/jora/vol3/iss1/4

Barney, J. B. (1991). Firm resources and sustained competitive advantage. Journal of Management, 17: 99-120.

Barney, J. B. (2001). Is the resource-based "view" a useful perspective for strategic management research? Yes. Academy of management review. 26 (1), 41-56.

Barney, J. B. (2013). Firm resources and sustained competitive advantage. Journal of Management, 17 (1), 99-120.
Biles, G. E. \& Holmberg, S. R. (2017). Strategic human resource planning. Glenn Ridge, New Jersey: Thomas Horton and Daughters.

Bjorkman, R.I (2009). Strategy and human resource management. Bristol: Palgrave.

Cole, (2012). Impact of Recruitment and selection in Canada (5th ed). Canada: Nelson Education Ltd.

Djabatey, E.N. (2012). Impact of recruitment and selection practices of organizations: A case study of HFC Bank (GH) Ltd. Unpublished thesis submitted to the Institute of Distance Learning, Kwame Nkrumah University of Science and Technology. Ghana:

Ehlers \& Lazenby (2014). Impact of recruitment and selection practices of organizations .Talent deficiency syndrome: Effective executive. ICFAI Press, 8 (5), 12-20.

Ekwoaba, Ikeiji, \& Ufoma (2015), Impact of recruitment and Selection on Organizational Peformance, a study of Fidelity Bank Plc. Global Journal of Human Resource Management Vol.3, No.2, pp.22-33 from www.eajournals.org

Ezeali, B. O \& Esiagu, L. N (2010). Impact of recruitment and selection on train maintenance: Human capital management strategy in the 12st century. Onitsha: Book Point Limited.

Gamage, A. S. (2014). Recruitment and selection practices in manufacturing SMEs in Japan: An analysis of the link with business performance. Ruhuna Journal of Management and Finance, $1(1), 37-52$

Gibson (2009), Bringing corporate organizational culture to the bottom line. Organizational Dynamics, 3(2), 5-22.

Henry, O., \& Temtime, Z. (2009). Recruitment and selection practices in SMEs: Empirical evidence from a developing country perspective. Advances in Management, 3(2), 52-58.

Kaplan and Norton (2015). Impact of recruitment and selection on train maintenance: A test of a mediating model in the Greek manufacturing

95 This work is licensed under a Creative Commons Attribution 4.0 International License. 
context. International Journal of Human Resource Management, 17, 1223-1253

Mathis, D.J (2009), role of employee performance in enhancing organizational growth. Human Resource Management Journal, 3(2), 42-54.

Mokaya, J.R. Mukhweso, F.E \& Njuguna, F.O (2014), Impact of Recruitment and Selection on Organizational Performance. (5th Edition, Essex: Pearson Education.

Mullins, J.L. (2017). Impact of recruitment and selection on employees' innovation. London: Prentice Hall.

Nigerian Railway Corporation Bill (2016) from https://www.legalnaija.com/search/label/Nigeri an\%20Railway\%20Corporation\%20Bill\%2020 16

Niven, M.A. (2016), Impact of Recruitment and Selection on Employees' Innovation: A case of readymade garment manufacturers and exporters in Lahore. Pakistan Report, London: HMS

Obikeze, S. O. \& Obi, E. A. (2014). Public administration and Train Maintenance in Nigeria. A developmental Approach; Onitsha: Book Point Limited.

Omisore, L.T and Okofu, K.R (2012). The impact of recruitment and selection on organizational performance: A study of Nigeria Public Service. International Journal of Arts and Humanities, 1 (1), 79-94.
Petts, J.I (2012) Fairness in employment selection: A comparison of UK and USA experience. In. Smith, M., Robertson, I. T. (Eds) Advances in selection and assessment.

Plewa, S. P. (2012). Impact of recruitment and selection on communication: controversies and applications. Port Elizabeth, S.A: Prentice Hall.

Sinha, V. \& Thaly, P. (2013). A review on changing trend of employee innovationto enhance the quality of hiring in global organizations. Management, 18(2), 141-156.

Subbarao, P. (2015). Essentials of effective communication and industrial relation. Mumbai: Himalaya Publications.

Yamane, T. (1967). Statistics: An Introductory Analysis, 2nd Edition, New York: Harper and Row.

Wanyama, P. M., (2009). The relationship between HR Practices and firm performance: Examining causal order. Personnel Psychology Journal, 58(2), 409-47.

Xiucheng, A. Y. (2012). Impact of Recruitment and selection on communication: Current status and future directions. Human Resource Management Review, 10 (4), pp. 353-382.

96 This work is licensed under a Creative Commons Attribution 4.0 International License. 
APPENDIX I

Correlations Coefficients

\begin{tabular}{llllllll}
\hline & TMS & TM & EI & CM & RS & RSP & SP \\
TMS & 1 & & & & & & \\
TM & .503 & 1 & & & & & \\
EI & .024 & .576 & 1 & & & & \\
CM & .677 & .110 & .951 & 1 & & & \\
RS & .448 & .995 & .026 & .260 & 1 & & \\
RSP & .027 & .811 & .500 & .597 & .766 & 1 & .237 \\
SP & .027 & .122 & .381 & .024 & .972 & .237 \\
\hline
\end{tabular}

*. Correlation is significant at the 0.05 level (2-tailed).

Source: SPSS output

Key:

TMS Timely Movement Schedule of Trains

TMS

by the employees

RS Recruitment Source

TM Train Maintenance

EI Employee Innovation

RSP

Recruitment and Selection Policy

CM Communication

RSC $\begin{array}{ll}\text { Recruitment } \\ \text { Communication }\end{array}$

\section{APPENDIX II}

Population Distribution across Departments in the Corporation.

\begin{tabular}{|c|c|c|c|c|}
\hline DEPT & NO OF STAFF & $\begin{array}{l}\text { QUESTIONNAIRE } \\
\text { DISTRIBUTED }\end{array}$ & $\begin{array}{l}\text { NO OF } \text { OUESTINNAIRE } \\
\text { RETRIEVED }\end{array}$ & SAMPLE SIZE \\
\hline Civil Engineering Department & 65 & 18 & 13 & 11 \\
\hline $\begin{array}{l}\text { Mechanical/Electrical } \\
\& \text { Signal } \\
\text { Telecommunication } \\
\text { Department }\end{array}$ & 79 & 27 & 26 & 26 \\
\hline $\begin{array}{l}\text { Operation and Commercial } \\
\text { Department, }\end{array}$ & 80 & 35 & 35 & 34 \\
\hline $\begin{array}{l}\text { Finance and Account } \\
\text { Department }\end{array}$ & 72 & 28 & 28 & 28 \\
\hline $\begin{array}{ll}\text { Administration } & \text { /Human } \\
\text { Resource } & \end{array}$ & 84 & 37 & 37 & 37 \\
\hline New line Department & 66 & 26 & 26 & 26 \\
\hline $\begin{array}{ll}\text { Corporate } & \text { Planning } \\
\text { Department } & \\
\end{array}$ & 70 & 35 & 35 & 35 \\
\hline Audit Department & 73 & 35 & 35 & 35 \\
\hline Medical Department & 67 & 19 & 17 & 16 \\
\hline Total & 656 & 260 & 252 & 248 \\
\hline
\end{tabular}

Source: Field Survey, 2020

97 | This work is licensed under a Creative Commons Attribution 4.0 International License. 